\title{
AVALIAÇÃO DE SUBSIDIÁRIAS ESTRANGEIRAS EM EMPREENDIMENTOS MULTINACIONAIS: UM ESTUDO DE CASO EM 28 PAÍSES
}

\section{EVALUATION OF FOREIGN SUBSIDIARIES IN MULTINATIONAL COMPANIES: A CASE STUDY IN 28 COUNTRIES}

\author{
SAMANTHA MELONI \\ Mestre em Ciências Contábeis pela \\ Fundação Escola de Comércio Álvares Penteado \\ E-mail: smeloni@yahoo.com \\ ELIONOR JREIGE WEFFORT \\ Doutora em Ciências Contábeis pela Universidade de São Paulo \\ Professora do Programa de Mestrado da \\ Fundação Escola de Comércio Álvares Penteado \\ E-mail: eweffort@directnet.com.br
}

\author{
ANTONIO BENEDITO OLIVEIRA \\ Doutor em Contabilidade pela Universidade de São Paulo \\ Professor do Departamento de Contabilidade da \\ Pontifícia Universidade Católica/SP \\ Email: absolive@gmail.com

\section{SIRLEI LEMES} \\ Doutora em Contabilidade pela Universidade de São Paulo \\ Professora da Faculdade de Ciências Contábeis da \\ Universidade Federal de Uberlândia \\ E-mail: sirlemes@ufu.br
}

\section{Resumo}

O aumento no número de companhias multinacionais tem trazido vários desafios para a contabilidade. Por exemplo, esse tipo de empreendimento cross-border demanda cada vez mais informação contábil para tomada de decisão, especialmente aquelas concernentes à avaliação de desempenho de subsidiárias estrangeiras. O objetivo deste artigo é analisar os fatores que, na percepção dos gestores, impactam a análise de desempenho das subsidiárias estrangeiras pela matriz em uma determinada companhia multinacional. Também foram testadas as relações entre as dificuldades apontadas pelos gestores e os indicadores econômicos e culturais dos países da amostra. Para consecução do objetivo, foram enviados questionários para a matriz (nos Estados Unidos) e para 28 de suas subsidiárias estrangeiras na Europa, Ásia, África, América Latina e América do Norte de uma companhia multinacional do ramo de bebidas e alimentos. Os resultados obtidos indicam o desconforto dos gestores especialmente em relação ao impacto dos tributos, conversão da moeda e critérios de avaliação dos ativos diferidos sobre a avaliação de desempenho. 0 indicador econômico que mais claramente apresentou relação com o nível de satisfação dos gestores foi a taxa de inflação do país da subsidiária correspondente. Os valores culturais não apresentaram relação com a percepção dos gestores.

Palavras-chave: avaliação; subsidiárias estrangeiras; empreendimentos multinacionais.

\begin{abstract}
The increase in the number of multinational companies has been setting accounting many challenges. For instance, this kind of undertaking called cross-border is always demanding accounting information before a decision is made, specially those related to foreign subsidiaries development evaluation. The objective of this paper is to analyse the facts that, according to managers, influence the analysis of foreign subsidiaries development evaluation by the headquarters, in a certain multinational company. It was also tested the relation between the difficulties pointed by the managers and the economic and cultural indicators of the countries in the sample. The objective was obtained through questionnaires from a multinational company in the field of food and beverages which were sent to the headquarters (in the US) and to 28 foreign subsidiaries in Europe, Asia, Africa, South America and North America. The results obtained point out to the distress of the managers mainly to what is related to the impact of tributes, currency conversion and the deferred assets evaluation criteria about the development evaluation. The economic indicator that showed a clear relation to the level of satisfaction from the managers was the inflation rate of the correspondent subsidiary country. The cultural values haven't shown any relation to the managers' perception.
\end{abstract}

Key words: foreign subsidiaries, evaluation, multinational undertaking. 


\section{INTRODUÇÃO}

0 aumento do volume do comércio mundial de bens e serviços e do fluxo diário de capitais, ocasionado especialmente pela expansão da tecnologia e pela diminuição dos preços na área de comunicação, proporcionou maior oportunidade na criação de empreendimentos multinacionais. Esse tipo de negócio passou a ter novos tipos de controles gerenciais como, por exemplo, a avaliação das empresas subsidiárias no exterior com base nas informações contábeis. Como conseqüência, surge a necessidade de informações que atendam à multiplicidade de usuários localizados nas diversas subsidiárias das empresas multinacionais, provocando a criação de relatórios contábeis distintos de acordo com o país sob análise.

Nesse contexto, o presente artigo tem como objetivo principal analisar os fatores que impactam a análise de desempenho de subsidiárias estrangeiras pela matriz em um determinado empreendimento multinacional. De forma complementar, foram estabelecidos dois objetivos específicos para esta pesquisa: (a) comparar a percepção da matriz e das subsidiárias estrangeiras quanto às dificuldades na avaliação de desempenho em um determinado empreendimento multinacional e; (b) verificar a relação entre as percepções dos gestores, indicadores econômicos e valores culturais dos países de suas subsidiárias.

O estudo pode ser justificado considerando-se aspectos relativos à construção do conhecimento científico e à aplicação prática. Contribui para a construção do conhecimento científico na medida em que a pesquisa identifica quais fatores possuem relação com a satisfação de gestores quanto à avaliação de desempenho de subsidiárias estrangeiras realizada pela matriz, área ainda pouco explorada pela literatura nacional e estrangeira.

No tocante à sua aplicação prática, este estudo pode auxiliar os gestores de empreendimentos multinacionais a identificar pontos que demandam maior atenção, especialmente no que concerne à utilização de indicadores de desempenho de subsidiárias em países diferentes.

\section{ESTUDOS ANTERIORES}

Há uma variedade de termos utilizados para descrever companhias que estão envolvidas em negócios internacionais como, por exemplo, empreendimentos multinacionais (MNE's), corporações multinacionais (MNC's) e corporações transnacionais (TNC's). De acordo com Radebaugh e Daniels (1998, p. 18), o termo corporações multinacionais é utilizado na área de negócios internacionais, sendo sinônimo de empreendimentos multinacionais, ou seja, companhias que possuem uma visão global do mercado e da produção internacional. Já as companhias transnacionais são definidas como companhias gerenciadas nacionalmente, porém, em diferentes países (ver, por exemplo, GRIFFIN e PUTSAY, 1999).

De acordo com Radebaugh e Gray (1997, p. 24), os empreendimentos multinacionais são as companhias que possuem a visão mundial de produção na busca de matérias-primas, componentes e de mercado final (nesse sentido, também FISCHER et. al., 1999). Os autores mencionam que não há um consenso de quanto das vendas, ativos, lucros e empregados deveriam estar situados no exterior para que a empresa seja considerada efetivamente uma multinacional. Contudo, algo inferior a $10 \%$ destes 
indicadores provavelmente seria suficiente para excluir a companhia do grupo das multinacionais. Esse é o conceito adotado por este artigo e que guiou a escolha da companhia objeto do estudo de caso.

O ponto inicial para a conceituação de subsidiárias é tentar entender como elas estão conectadas à matriz. De acordo com Birkinshaw e Hood (1998), estudos realizados nos anos 1970 e 1980 evidenciavam alguns fatores da relação subsidiária-matriz, tais como: centralização, formalização e controle/coordenação.

Nobes e Parker (1998, p. 496) explicam que um sistema de gerenciamento complexo pode resultar em frustração pela média gerência e tempo desperdiçado pela equipe em função do mau gerenciamento. Paralelamente a isso, a empresa matriz não deveria requerer apenas informações simples de suas subsidiárias, pois a matriz deve manter o controle sobre as decisões positivas e negativas das subsidiárias para que o relacionamento entre as suas pontas seja aberto e de auxílio. Isso significa que deve haver um senso comum entre matriz e subsidiárias a fim de que o gerenciamento seja eficiente e eficaz.

Nota-se que a eficiência da execução do controle e da gestão das subsidiárias está fortemente relacionada à boa definição e ao bom entendimento das regras, tanto para as subsidiárias quanto para a matriz, e uma definição balanceada de poder na tomada de decisão. Por outro lado, fatores como regulamentações governamentais às quais estão sujeitas as subsidiárias estrangeiras e normas contábeis diferentes da matriz podem configurar uma dificuldade para alcançar tal eficiência.

Relacionando o estabelecimento de controles com a informação contábil, Harzing (1999) afirma que se pode encontrar diferentes mecanismos de controle de subsidiárias no contexto das empresas multinacionais, porém, tais fatores devem ser certamente considerados pela contabilidade.

Destacando a influência da matriz na gestão das subsidiárias, Buckley et al. (1998, p. 15) consideram dois grandes estilos de desenvolvimento das subsidiárias delineados pela matriz: integrado e hierárquico. 0 primeiro assume que a subsidiária é a responsável por suas funções principais, tais como: pesquisa e desenvolvimento, manufatura e mercado. Já no modelo hierárquico, a matriz conduz e lidera a subsidiária a fim de torná-la especialista em determinada função e ser um centro de excelência.

A avaliação de desempenho em empreendimentos multinacionais constitui um item de grande discussão no contexto dos negócios e a contabilidade serve como base, provendo informações para que essa análise seja feita, ou seja, o grande banco de dados que alimenta a avaliação de desempenho é a contabilidade.

A exemplo disso, Lindholm (2000) e Yu (2005) analisaram o gerenciamento de performance e as relações entre subsidiárias de acordo com padrões contábeis estabelecidos pela matriz. Lindholm (2000), por exemplo, realizou uma pesquisa acerca da transferência de características entre os países no contexto de uma multinacional. 0 autor analisou o gerenciamento de performance apenas no processo ligado a recursos humanos, não envolvendo outras áreas como, por exemplo, a área contábil e a financeira da empresa. Já Yu (2005) examinou as relações entre as subsidiárias de uma empresa multinacional com sede em Taiwan de acordo com as regras e padrões contábeis estabelecidos pela matriz. Com a utilização de análise de regressão, foi evidenciado que os diferentes tipos de indústria, o grau de integração entre a matriz e as subsidiárias, a localização e o grau de dependência das subsidiárias com relação à matriz constituem os mais importantes fatores que promovem a satisfação dos gestores das subsidiárias com relação às atividades realizadas para atender aos objetivos da empresa.

Choi e Mueller (1992) aplicaram um questionário abrangendo oito práticas de 
empresas multinacionais e dividiram as respostas em duas categorias de análise: as empresas dos Estados Unidos e as demais. Os resultados obtidos abordaram aspectos relativos a: objetivos do sistema de avaliação de performance; critérios de performance; volatilidade da moeda; avaliação de performance e inflação; outros problemas no ambiente organizacional; padrões de performance; satisfação com os sistemas de avaliação existentes. Considerando-se esses diversos aspectos e, sabendo-se que cada empresa possui suas especificidades, para Choi e Mueller (1992), a matriz deve saber lidar com as características próprias de cada subsidiária, buscando a eficiência dos processos a fim de alinhar as regras de conduta e gestão globais e alcançar os resultados propostos.

Choi e Czechowicz (1983) mencionam que a avaliação de performance em subsidiárias está mais ligada a uma arte do que a uma ciência, e sua complexidade aumenta quando as operações ocorrem no âmbito multinacional.

Borkowski (1993) defende a idéia de que empresas multinacionais devem ter um tratamento diferente para avaliação de performance quando comparadas a empresas domésticas. A autora caracteriza a importância da avaliação diferenciada para as multinacionais utilizando critérios econômicos, políticos e ambiente operacional distintos.

Diante disso, e sabendo-se que cada empresa possui suas especificidades, a matriz deve saber lidar com as características próprias de cada subsidiária, buscando a eficiência dos processos a fim de alinhar as regras de conduta e gestão globais e alcançar os resultados propostos.

Conforme mencionado anteriormente, o presente trabalho visa pesquisar o alinhamento das percepções dos gestores das subsidiárias e da matriz na avaliação de desempenho das subsidiárias estrangeiras.

Como o objetivo da avaliação de desempenho é o de analisar o desempenho dos funcionários (ou de uma subsidiária, que é o caso deste trabalho), a informação torna-se elemento primordial no processo. Na empresa analisada, a informação contábil financeira é a utilizada para avaliar o desempenho das subsidiárias.

\subsection{METODOLOGIA DA PESQUISA}

Quanto à tipologia da pesquisa, este trabalho se classifica como um estudo exploratório. No tocante aos procedimentos técnicos de coleta de dados, este se delineia como um estudo de caso, pois coloca sob foco um empreendimento multinacional, para o qual se buscou um conhecimento aprofundado e detalhado do processo de avaliação das suas subsidiárias estrangeiras.

Por conveniência de acesso aos dados, foi realizada uma pesquisa de campo em uma companhia multinacional do setor de alimentos e bebidas por meio de questionários enviados separadamente à matriz, com sede nos Estados Unidos, e às suas subsidiárias estrangeiras, a fim de analisar a percepção dos gestores em relação às principais dificuldades encontradas na avaliação de desempenho das subsidiárias situadas em países diferentes. Essa companhia possui subsidiárias em 61 países, sendo a matriz localizada nos Estados Unidos. Durante o período de junho de 2005 a maio de 2006 a companhia obteve lucro de US\$ 1,5 bilhão aproximadamente.

Foram recebidos 65 questionários de subsidiárias estrangeiras de 28 países Alemanha, Argentina, Austrália, Brasil, Chile, Colômbia, Costa Rica, Egito, Espanha, Honduras, Hong-Kong, Indonésia, Inglaterra, Itália, Japão, Malásia, Marrocos, México, Nicarágua, Paraguai, Polônia, Rússia, Singapura, Suíça, Tailândia, Taiwan, Turquia e Venezuela - representando $45,9 \%$ países onde a companhia mantém subsidiárias. Uma vez 
que estes questionários foram enviados às áreas responsáveis pela elaboração de relatórios para a matriz, o número de respondentes por país variou de 1 a 9 , dependendo do porte da área. Da matriz norte-americana, foram recebidos 4 questionários, totalizando, portanto, 69 respondentes da pesquisa.

A escala likert de mensuração da percepção da matriz e subsidiárias utilizada nos questionários variou de 1 a 5 , em que 1 indicava pouquíssima ou nenhuma dificuldade/peculiaridade e 5 indicava muitíssima dificuldade/peculiaridade. Adotou-se para o termo peculiaridade o sentido de definir as especificidades e atributos particulares dos itens pesquisados na matriz e nas subsidiárias. Com isso, quanto maior a média ponderada calculada, maiores as dificuldades/peculiaridades que a matriz e as subsidiárias percebem ter, demonstrando menor satisfação.

Nos questionários foram incluídos alguns itens pré-estabelecidos, tais como: conversão da moeda, cenário econômico, critérios de reconhecimento e mensuração de ativos fixos e diferidos e impostos. Para não limitar a pesquisa somente a estes fatores, foram contemplados campos descritivos para que o respondente indicasse algum outro item que julgasse relevante.

Adicionalmente, foi aplicado um questionário de cultura enviado à matriz e às subsidiárias. Este questionário foi proposto por Hofstede (2005) e contempla 26 questões. Os dados foram calculados, para cada país, de acordo com a metodologia proposta por Hofstede, e comparados com os dados da pesquisa do autor. Porém, o número restrito de respondentes por país, inerente à própria metodologia adotada, gerou resultados pouco consistentes. Optou-se, por isso, em descartar esses resultados da amostra e utilizar os indicadores obtidos nas pesquisas de Hofstede (1984, 1991).

O Quadro 1 a seguir resume as variáveis selecionadas para análise com os itens correspondentes dos questionários. 


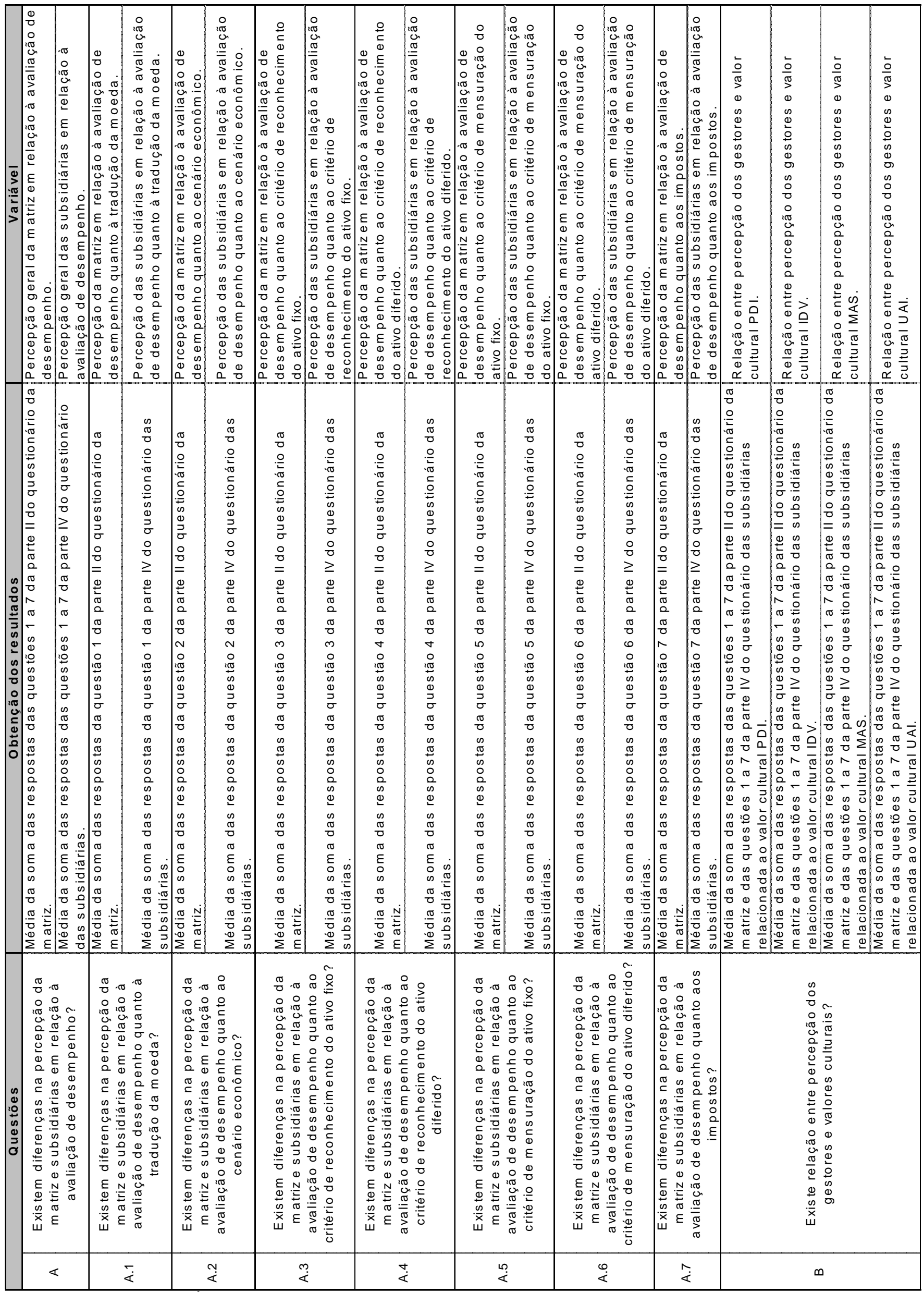

QUADRO 1 - Variáveis da pesquisa 
As percepções dos gestores - variáveis do Quadro 1 - foram confrontadas com alguns indicadores econômicos dos países onde estão localizados a matriz e as subsidiárias da amostra para verificar se há relação entre eles, como indica o Quadro 2.

\begin{tabular}{|c|c|c|c|}
\hline \multicolumn{2}{|r|}{ Questões } & Obtenção dos resultados & Variável \\
\hline C. 1 & $\begin{array}{l}\text { Existe relação entre percepção dos } \\
\text { gestores quanto à tradução da moeda e } \\
\text { inflação? }\end{array}$ & $\begin{array}{l}\text { Média da soma das respostas da questão } 1 \text { da parte II do questionário da matriz } \\
\text { e da questão } 1 \text { da parte IV do questionário das subsidiárias relacionada à } \\
\text { inflação de } 2004 \text {. }\end{array}$ & $\begin{array}{l}\text { Relação entre percepção dos gestores quanto à } \\
\text { tradução da moeda e inflação. }\end{array}$ \\
\hline C.2 & $\begin{array}{l}\text { Existe relação entre percepção dos } \\
\text { gestores quanto à tradução da moeda e } \\
\text { câmbio? }\end{array}$ & $\begin{array}{l}\text { Média da soma das respostas da questão } 1 \text { da parte Il do questionário da matriz } \\
\text { e da questão } 1 \text { da parte IV do questionário das subsidiárias relacionada ao } \\
\text { câmbio de } 17 \text { fev. } 2005 \text {. }\end{array}$ & $\begin{array}{l}\text { Relação entre percepção dos gestores quanto à } \\
\text { tradução da moeda e câm bio. }\end{array}$ \\
\hline C. 3 & $\begin{array}{l}\text { Existe relação entre percepção dos } \\
\text { gestores quanto ao cenário econômico e } \\
\text { PIB? }\end{array}$ & $\begin{array}{l}\text { Média da soma das respostas da questão } 2 \text { da parte II do questionário da matriz } \\
\text { e da questão } 2 \text { da parte IV do questionário das subsidiárias relacionada ao PIB } \\
\text { de } 2004 \text {. }\end{array}$ & $\begin{array}{l}\text { Relação entre percepção dos gestores quanto ao } \\
\text { cenário econômico e PIB. }\end{array}$ \\
\hline C. 3 & $\begin{array}{l}\text { Existe relação entre percepção dos } \\
\text { gestores quanto ao cenário econômico e } \\
\text { investimentos externos? }\end{array}$ & $\begin{array}{l}\text { Média da soma das respostas da questão } 2 \text { da parte II do questionário da matriz } \\
\text { e da questão } 2 \text { da parte IV do questionário das subsidiárias relacionada aos } \\
\text { investim entos externos de } 2003 \text {. }\end{array}$ & $\begin{array}{l}\text { Relação entre percepção dos gestores quanto ao } \\
\text { cenário econômico e investim entos externos. }\end{array}$ \\
\hline C. 4 & $\begin{array}{l}\text { Existe relação entre percepção dos } \\
\text { gestores quanto ao cenário econômico e } \\
\text { im portações? }\end{array}$ & $\begin{array}{l}\text { Média da soma das respostas da questão } 2 \text { da parte II do questionário da matriz } \\
\text { e da questão } 2 \text { da parte IV do questionário das subsidiárias relacionada às } \\
\text { im portações de } 2003 \text {. }\end{array}$ & $\begin{array}{l}\text { Relação entre percepção dos gestores quanto ao } \\
\text { cenário econômico e importações. }\end{array}$ \\
\hline C.5 & $\begin{array}{l}\text { Existe relação entre percepção dos } \\
\text { gestores quanto ao cenário econômico e } \\
\text { exportações? }\end{array}$ & $\begin{array}{l}\text { Média da soma das respostas da questão } 2 \text { da parte II do questionário da matriz } \\
\text { e da questão } 2 \text { da parte IV do questionário das subsidiárias relacionada às } \\
\text { exportações de } 2003 \text {. }\end{array}$ & $\begin{array}{l}\text { Relação entre percepção dos gestores quanto ao } \\
\text { cenário econômico e exportações. }\end{array}$ \\
\hline
\end{tabular}

QUADRO 2 - Relação da percepção dos gestores com indicadores econômicos dos países

De acordo com o Quadro 2, foram destacados os seguintes indicadores econômicos dos países: inflação; câmbio em relação ao dólar americano; produto interno bruto; investimentos externos no país; exportações do país (percentual sobre o PIB); importações do país (percentual sobre o PIB).

A análise das variáveis, bem como sua relação com os fatores citados acima, será aprofundada na análise dos resultados.

Devem ser observadas duas limitações na presente pesquisa: a primeira decorrente da própria estrutura organizacional da companhia objeto do estudo de caso e a segunda em virtude da utilização de alguns dados secundários.

Foram obtidas poucas respostas por país em função da própria estrutura da empresa, uma vez que a gerência da contabilidade tende a ser enxuta e não fazia sentido enviar o questionário a outras áreas e posições.

Para os valores culturais, conforme mencionado anteriormente, em função do pequeno número de respondentes da amostra por país, os índices de cultura calculados sofreram muitas distorções, o que inviabilizaria a análise. Optou-se por utilizar os dados coletados por Hofstede $(1984,1991)$ porque, apesar das críticas, eles foram largamente utilizados em estudos na área de negócios (ver BASKERVILLE, 2003)

Quanto à utilização de dados secundários para os indicadores econômicos dos países, tomou-se a cautela de que esses fossem provenientes de fontes notórias e confiáveis (World Bank).

\section{RESULTADOS OBTIDOS E ANÁLISE}

Foram feitas, inicialmente, averiguações para identificar o nível de satisfação das subsidiárias com relação à matriz, bem como das subsidiárias quanto à análise de desempenho realizada pela matriz, considerando as variáveis: conversão da moeda, cenário econômico, critérios de reconhecimento e mensuração de ativos fixos e diferidos e impostos. Posteriormente, foram realizados testes não paramétricos (por exemplo, Teste U de Mann-Whitney, Kruskal-Wallis) para verificar a relação entre as percepções dos gestores e os valores culturais predominantes e alguns indicadores econômicos dos países. 


\subsection{PERCEPÇÃO GERAL DOS GESTORES DA MATRIZ E DAS SUBSIDIÁRIAS ESTRANGEIRAS}

Foram tabulados alguns itens a fim de mensurar a percepção da matriz quanto às dificuldades encontradas na avaliação de desempenho das subsidiárias situadas em diversos países. Os resultados obtidos encontram-se na Tabela 1 a seguir.

Tabela 1 - Avaliação de desempenho: percepção da matriz (média ponderada)

\begin{tabular}{lcc}
\hline \multicolumn{1}{c}{ Pontos analisados matriz } & $\begin{array}{c}\text { Número } \\
\text { respostas }\end{array}$ & $\begin{array}{c}\text { Média } \\
\text { ponderada }\end{array}$ \\
\hline \hline Tradução moeda & 4 & 3,25 \\
Cenário econômico & 4 & 2,75 \\
Critério reconhecimento ativo fixo & 4 & 2,50 \\
Critério reconhecimento ativo diferido & 4 & 3,00 \\
Critério mensuração ativo fixo & 4 & 2,75 \\
Critério mensuração ativo diferido & 4 & 3,25 \\
Impostos & 4 & 3,75 \\
Outros & - & - \\
\hline \hline Total & $\mathbf{2 8}$ & $\mathbf{3 , 0 4}$ \\
\hline
\end{tabular}

A Tabela 1 traz primeiramente a soma pura das respostas e, na seqüência, com base no número de respondentes que participaram do questionário a média ponderada de respostas. Nota-se que em nenhum dos itens pesquisados a matriz demonstra índice total de satisfação (média ponderada entre 1 e 2). 0 fator que menos apresenta dificuldades na opinião da matriz quando da análise de desempenho dos gestores das subsidiárias é o critério de reconhecimento do ativo fixo. Ao contrário disso, o item que mais apresenta peculiaridades e dificuldades na visão da matriz são os impostos. Essas dificuldades muito provavelmente resultam da especificidade de tratamento dado em cada país.

$\mathrm{Na}$ Tabela 2, estão resumidos os resultados da percepção dos gestores das subsidiárias quanto às dificuldades encontradas na avaliação de desempenho realizada pela matriz.

Tabela 2 - Avaliação de desempenho: percepção das subsidiárias (média ponderada)

\begin{tabular}{lcc}
\hline \multicolumn{1}{c}{ Pontos analisados subsidiárias } & $\begin{array}{c}\text { Número } \\
\text { respostas }\end{array}$ & $\begin{array}{c}\text { Média } \\
\text { ponderada }\end{array}$ \\
\hline \hline Tradução moeda & 58 & 3,29 \\
Cenário econômico & 53 & 2,92 \\
Critério reconhecimento ativo fixo & 59 & 3,34 \\
Critério reconhecimento ativo diferido & 58 & 3,47 \\
Critério mensuração ativo fixo & 59 & 3,24 \\
Critério mensuração ativo diferido & 58 & 3,31 \\
Impostos & 58 & 3,57 \\
Outros & 4 & 4,75 \\
\hline \hline Total & $\mathbf{4 0 7}$ & $\mathbf{3 , 3 2}$ \\
\hline
\end{tabular}

Igualmente aos resultados obtidos com a matriz, nota-se que em nenhum dos itens pesquisados as subsidiárias demonstram índice total de satisfação. 0 fator que menos apresenta peculiaridades (dos sugeridos nesta pesquisa) na opinião das subsidiárias, quando da análise de desempenho de seus gestores pela matriz, é o cenário econômico. 
Também alinhado com os resultados da matriz, o item que mais apresenta peculiaridades e dificuldades na visão das subsidiárias são os impostos. De fato, este item é muito específico entre os países, o que gera descontentamento quando a matriz mensura e analisa o desempenho de acordo com os parâmetros norte-americanos, sem contemplar as especificidades de cada país.

No entanto, quatro respondentes das subsidiárias indicaram outros fatores que, em sua percepção, traziam dificuldades na avaliação de desempenho. Os fatores citados foram: GAAP como um todo, mensuração dos estoques e resultado diferido. Estes foram os pontos em que as subsidiárias mais sentiram dificuldades de acordo com a média de percepção $(4,75)$.

\subsection{PERCEPÇÃO DOS GESTORES QUANTO À CONVERSÃO DA MOEDA}

As subsidiárias situadas nos países Argentina, Austrália, Colômbia, Japão, Marrocos, Taiwan e Venezuela foram as que apresentaram maiores dificuldades e baixo índice de satisfação quanto ao item conversão da moeda na avaliação de desempenho. As subsidiárias inglesas e russas não responderam a esta questão.

A percepção dos gestores das subsidiárias e da matriz quanto à conversão da moeda foi correlacionada com os fatores inflação (período de 2004) e câmbio (conversão da moeda local do país com relação ao dólar, com data base de 17 fev. 2005).

Choi e Mueller (1992) aplicaram um questionário abrangendo oito práticas de empresas multinacionais; duas delas referiam-se à volatilidade da moeda e inflação. De acordo com a pesquisa, as empresas multinacionais norte-americanas e as demais multinacionais foram consistentes no tratamento das transações de lucros e perdas, ou seja, os ajustes das moedas foram considerados na mensuração da performance das subsidiárias. Porém, geralmente as empresas norte-americanas não realizam ajustes de inflação em suas subsidiárias; quando são realizados, tais ajustes limitam-se apenas ao orçamento. Já as multinacionais européias têm como prática ajustarem a inflação das subsidiárias e, posteriormente, efetuarem a conversão de acordo com a moeda da matriz.

A empresa matriz pesquisada no presente trabalho não considera os ajustes de moedas para avaliação de performance de suas subsidiárias. Todas as demonstrações e índices devem estar na moeda dólar, além de contemplar as práticas norte-americanas. Por meio da análise estatística, a relação entre conversão da moeda e inflação apresentou um nível descritivo de 0,024 , o que caracteriza diferentes respostas de acordo com a inflação do país analisado. Estatisticamente, pode-se aceitar o valor que delimita as diferenças entre as respostas como sendo de 0,05. Quanto menor os níveis descritivos, mais diferentes são as respostas pelo fator investigado, ou seja, mais forte relação a variável possui com o fator analisado.

Pode-se verificar com o Gráfico 1 a seguir que quanto maior a inflação do país, maior a dificuldade percebida pelos gestores na variável conversão da moeda. 


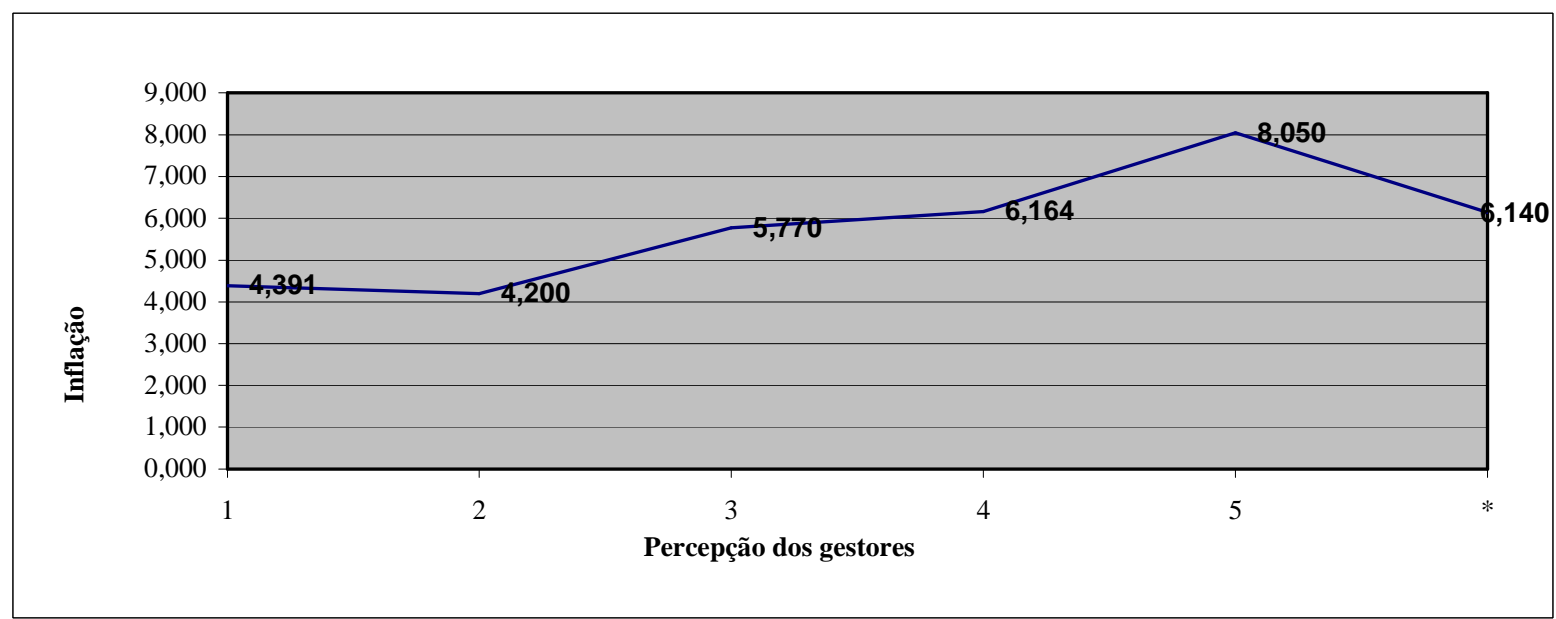

Gráfico 1 - Percepção dos gestores quanto à análise de desempenho: relação entre conversão da moeda e inflação

0 asterisco colocado no gráfico representa os países que possuíam o fator inflação, porém não foram obtidas respostas, por isso não fazem parte da curva de análise.

Já a análise da relação entre conversão da moeda e câmbio gerou um nível descritivo no valor de 0,367 , o que não permite afirmar que o câmbio possui relação com a percepção dos gestores quanto à variável conversão da moeda.

Portanto, pode-se concluir neste item que a percepção do item conversão da moeda sob a ótica da análise de desempenho está relacionada à inflação do país em que o respondente está situado.

\subsection{PERCEPÇÃO DOS GESTORES QUANTO AO CENÁRIO ECONÔMICO}

De acordo com a pesquisa, as subsidiárias que mais sentem dificuldades com relação à avaliação de desempenho quanto ao cenário econômico são as situadas na Colômbia, México e Polônia. Ao contrário disso, maiores índices de satisfação foram encontrados nas subsidiárias localizadas na Austrália, Indonésia e Malásia. A subsidiária inglesa não respondeu a esta questão.

A percepção dos gestores quanto ao cenário econômico foi correlacionada com os fatores PIB, investimentos externos, exportações e importações.

Tais fatores foram selecionados, pois constituem características dos países analisados e poderiam trazer alguma correlação com os resultados obtidos. Tal fato não impede a análise com outros fatores, como por exemplo, o risco do país.

Em nenhum dos fatores (PIB, investimentos externos, exportações e importações) pôde-se constatar um nível descritivo aceitável (abaixo de 0,05) para afirmar que existe relação entre a variável e os fatores analisados.

Por outro lado, verifica-se uma semelhança de percepção quando são comparados os fatores exportação e importação, de acordo com o Gráfico 2 a seguir: 


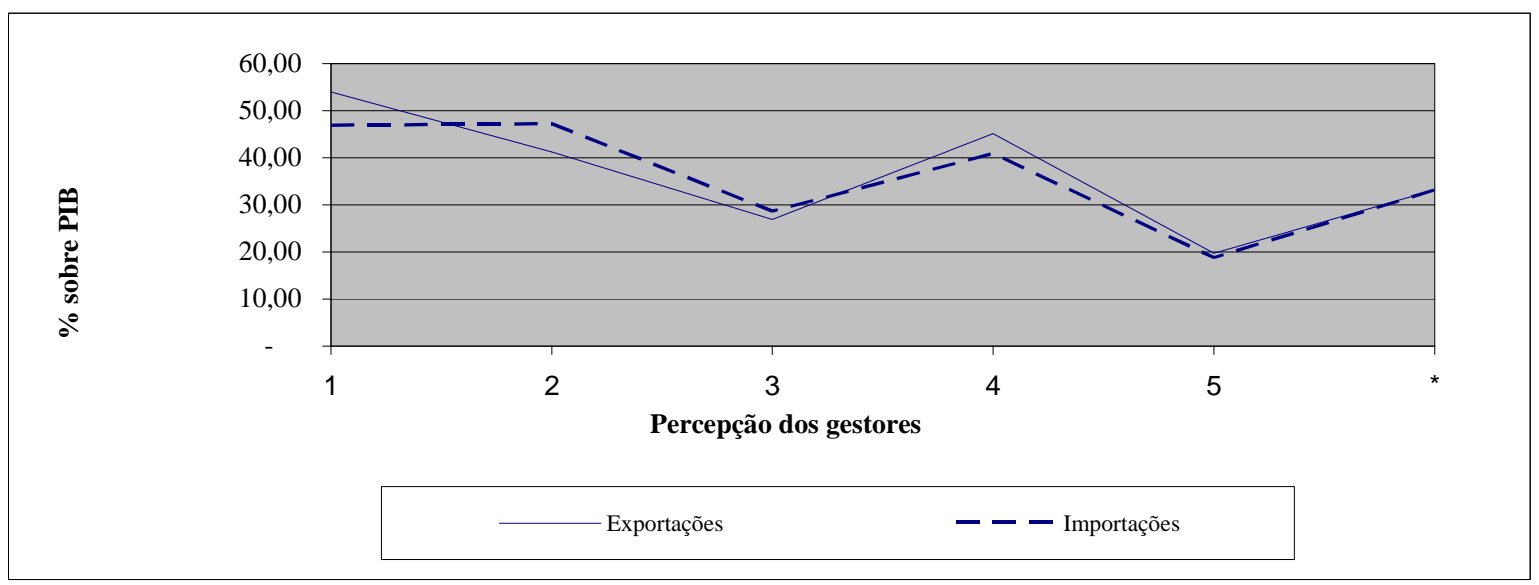

Gráfico 2 - Percepção dos gestores quanto à análise de desempenho: relação entre cenário econômico e importações/exportações

Como demonstrado no Gráfico 2, a curva que demonstra a percepção dos gestores com relação à exportação (\% de exportação sobre o PIB) é semelhante à relação com a importação (\% de importação sobre o PIB).

\subsection{PERCEPÇÃO DOS GESTORES QUANTO À MENSURAÇÃO E AO RECONHECIMENTO DO ATIVO FIXO}

A seguir é demonstrada nos Gráficos 3 e 4 a percepção dos gestores das subsidiárias por país quanto ao critério de reconhecimento e mensuração de ativo fixo na avaliação de desempenho:

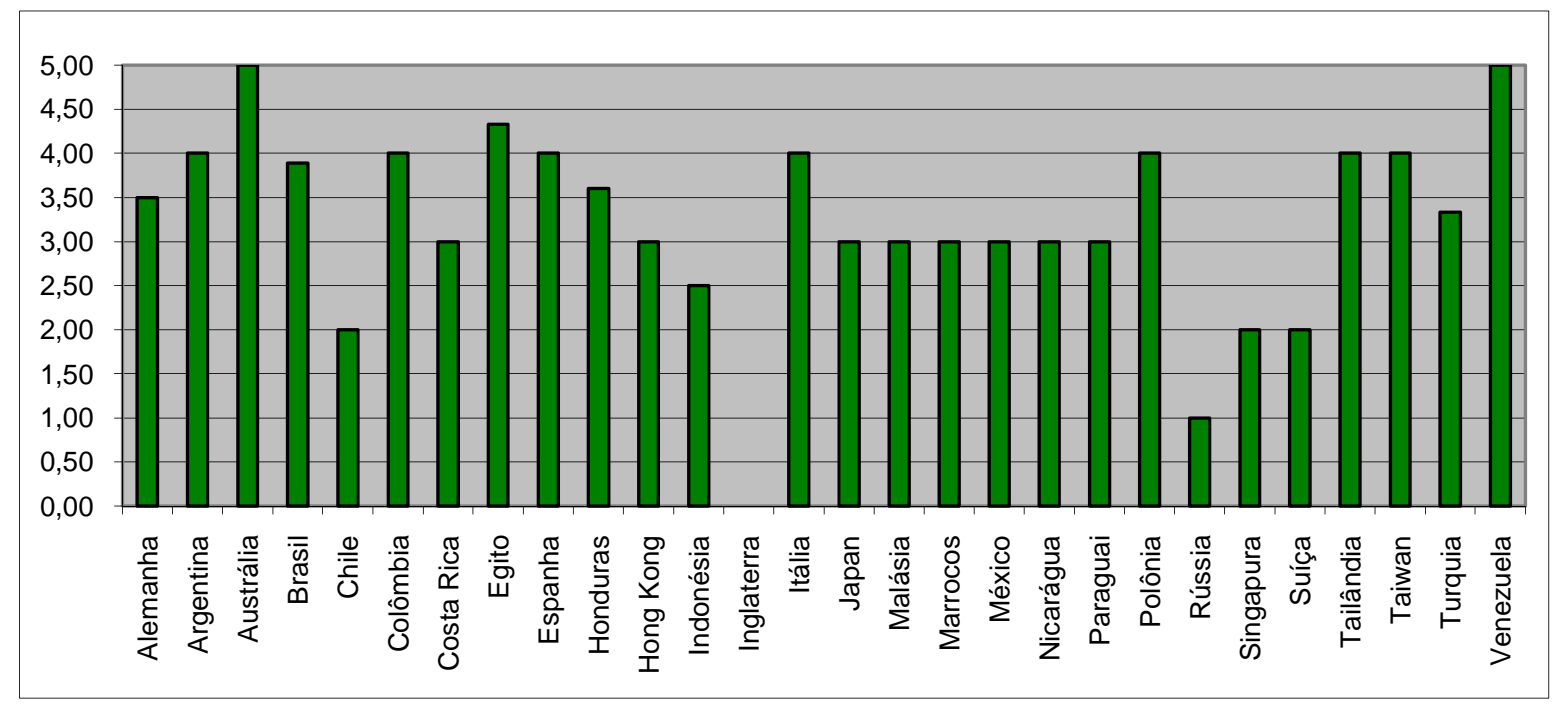

Gráfico 3 - Percepção das subsidiárias quanto ao impacto do critério de reconhecimento do ativo fixo na análise de desempenho

Pode-se perceber com o gráfico que as subsidiárias situadas nos países da Austrália, Egito e Venezuela foram as que demonstraram maior dificuldade no critério de 
reconhecimento do ativo fixo na análise de desempenho. Já as subsidiárias chilena, russa, suiça e de Singapura foram as que demonstraram menor dificuldade de adaptação neste item. Novamente, a subsidiária inglesa não respondeu à questão.

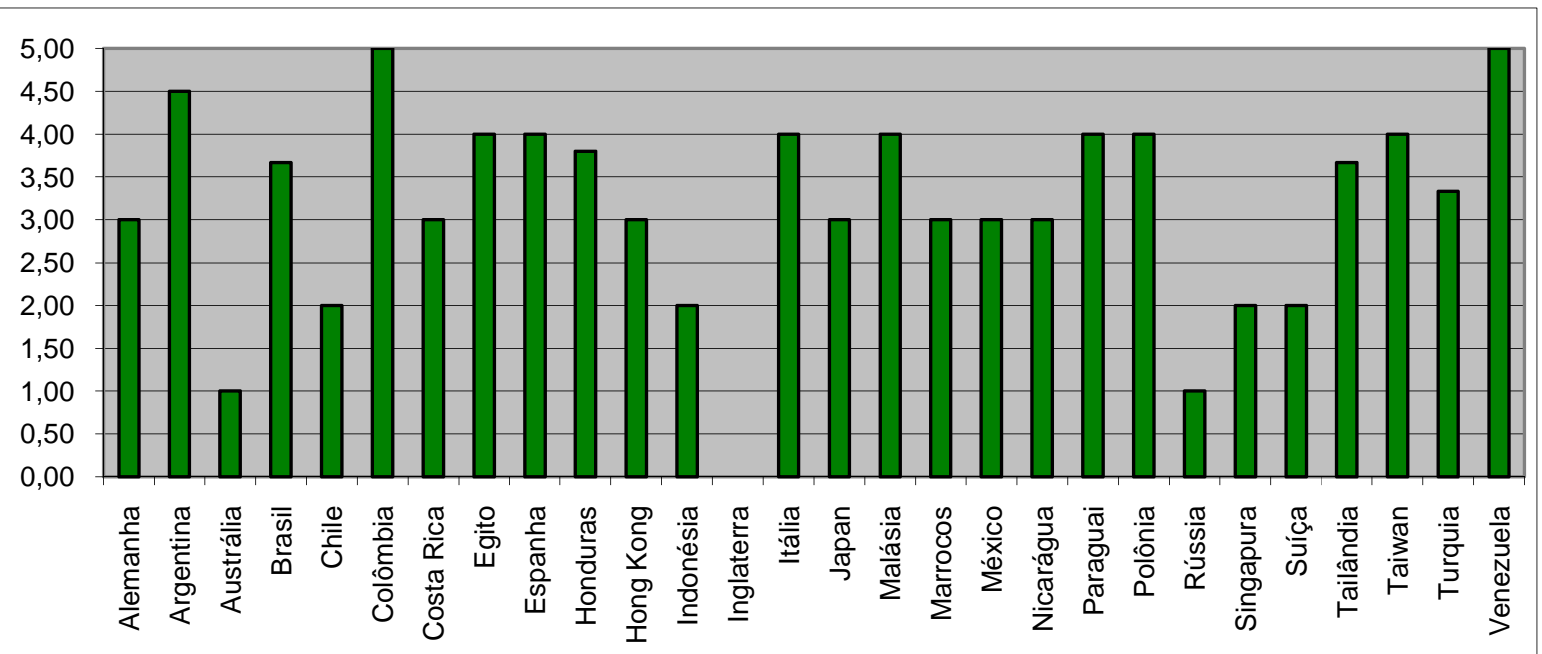

Gráfico 4 - Percepção das subsidiárias quanto ao impacto do critério de mensuração do ativo fixo na análise de desempenho

Com algumas semelhanças com o Gráfico 4, as grandes dificuldades quanto ao critério de mensuração do ativo fixo na análise de desempenho foram demonstradas pelas subsidiárias situadas na Argentina, Colômbia e Venezuela. No sentido oposto, aquelas que se sentiram mais confortáveis com relação ao item foram as autralianas e as russas. A subsidiária inglesa manteve a característica de não responder à questão.

Os ativos fixos possuem tratamento de reconhecimento diferenciado entre os países. No Brasil, por exemplo, um é reconhecido como ativo fixo, confome permite a legislação fiscal, se seu valor for superior a R\$326,61. Já nos EUA, as empresas delimitam este valor de acordo com sua necessidade e padrões estabelecidos. A empresa analisada estipula um montante mínimo de US\$ 5.000,00 para reconhecimento dos ativos como fixos.

Tal critério deve ser seguido por todas as subsidiárias, independentemente do país que estão situadas e da legislação local.

Portanto, a percepção dos países nos itens de reconhecimento e mensuração dos ativos fixos pode estar relacionada a este valor mínimo para reconhecimento, que, apesar de não obrigatório, é, uma prática adotada pela maioria das empresas brasileiras. Se a subsidiária não possuir limite mínimo para reconhecer um ativo, quando fizer os ajustes exigidos pela matriz, reclassificará parte de seus ativos para resultado, diminuindo seu lucro e prejudicando sua análise de desempenho.

Em termos estatísticos, a relação entre a percepção dos gestores das subsidiárias e da matriz com o critério de reconhecimento do ativo fixo e a percepção dos gestores com o critério de mensuração do ativo fixo é significante, pois apresentou nível descritivo abaixo de 0,05 .

\subsection{PERCEPÇÃO DOS GESTORES QUANTO À MENSURAÇÃO E AO RECONHECIMENTO DO ATIVO DIFERIDO}


A seguir é demonstrada nos Gráficos 5 e 6 a percepção dos gestores das subsidiárias por país quanto ao critério de reconhecimento e mensuração de ativo diferido, respectivamente, na avaliação de desempenho:

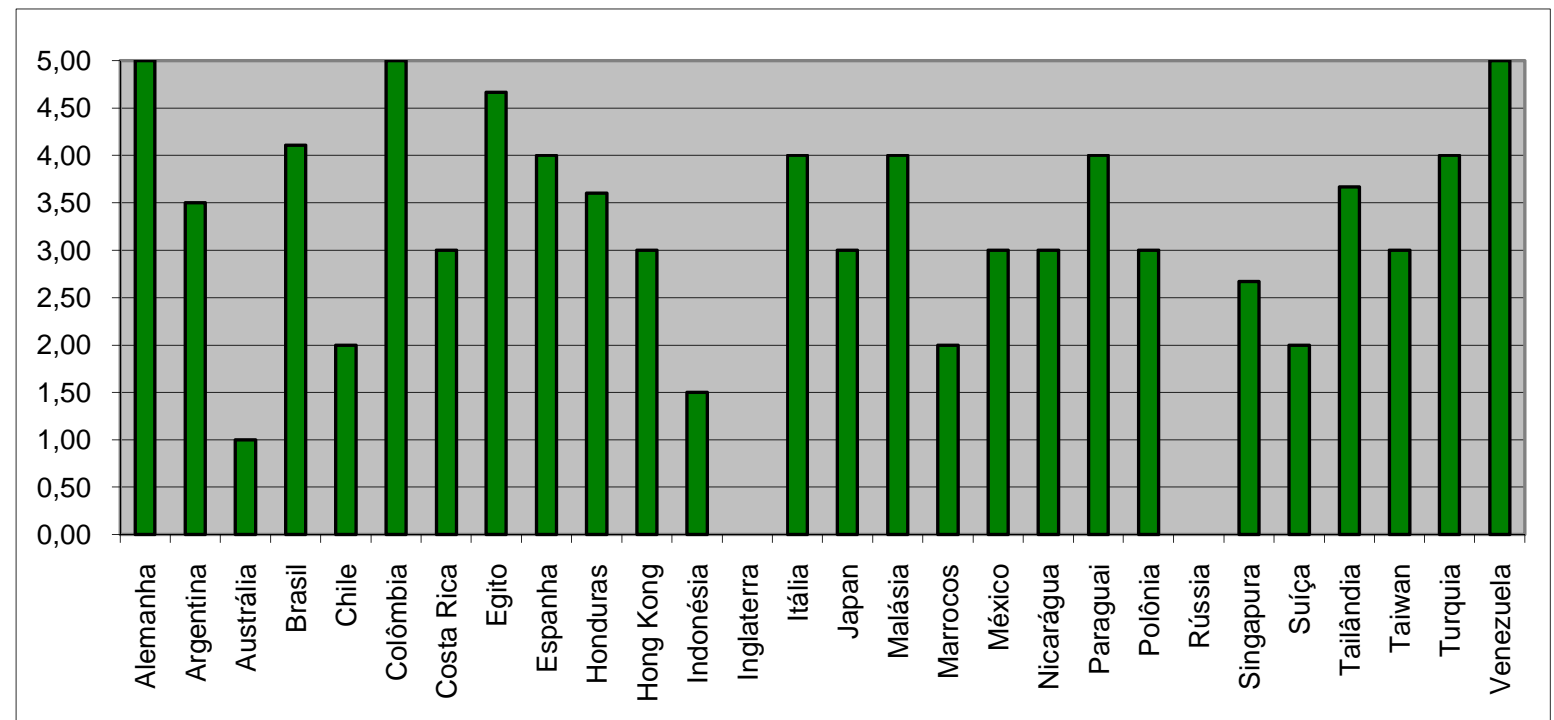

Gráfico 5 - Percepção das subsidiárias quanto ao impacto do critério de reconhecimento do ativo diferido na análise de desempenho

Nota-se, pelo Gráfico, que as subsidiárias situadas na Austrália e Indonésia demonstraram maior adaptação ao critério de reconhecimento do ativo diferido na análise de desempenho. Ao contrário disso, as subsidiárias situadas na Argentina, Colômbia, Egito e Venezuela demonstraram maiores dificuldades em se adaptar aos princípios norteamericanos para a análise de desempenho.

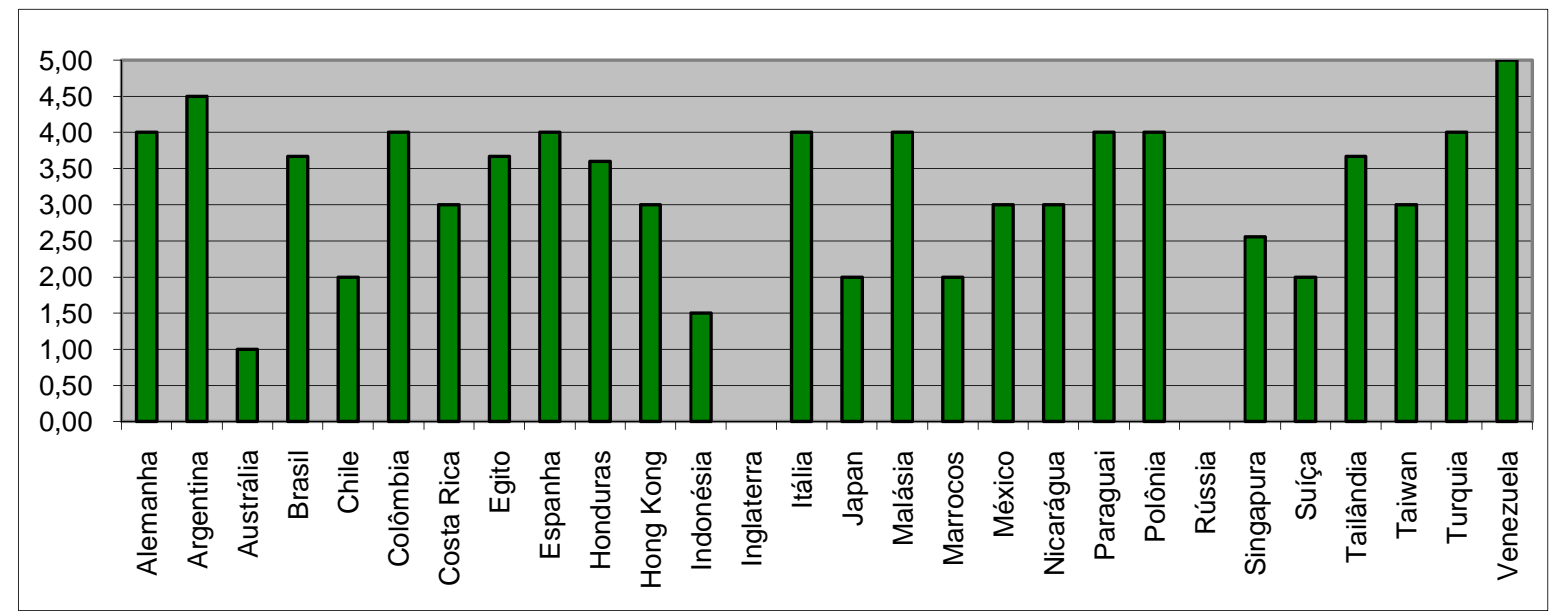

Gráfico 6 - Percepção das subsidiárias quanto ao impacto do critério de mensuração do ativo diferido na análise de desempenho

Assim como em relação ao impacto do critério de mensuração do ativo fixo na análise de desempenho (Gráfico 4), as subsidiárias argentina e venezuelana permanecem com baixo índice de satisfação também quanto ao critério de mensuração do ativo diferido na análise de desempenho. De maneira semelhante ao Gráfico 4, as subsidiárias situadas na Austrália e Indonésia demonstraram mais adaptação ao critério de mensuração do ativo diferido na análise de desempenho. 
As subsidiárias inglesa e russa não responderam a esta questão de percepção. Para as análises dos critérios de reconhecimento e mensuração do ativo diferido pode ser utilizado raciocínio similar ao caso anterior. A legislação norte-americana tende a não diferir ativos e reconhecer estes saldos no resultado. Com isso, aqueles países que, em sua legislação local diferem ativos, têm seu resultado diminuído quando fazem as devidas reclassificações para enquadrarem-se aos critérios da matriz. Tal fato faz com que os índices de desempenho diminuam, prejudicando sua análise perante a matriz. Em termos estatísticos, a relação entre a percepção dos gestores das subsidiárias e da matriz com o critério de reconhecimento do ativo diferido e a percepção dos gestores com o critério de mensuração do ativo diferido é significante, pois apresentou nível descritivo abaixo de 0,05 .

\subsection{PERCEPÇÃO DOS GESTORES QUANTO AOS IMPOSTOS}

O Gráfico 7 a seguir demonstra a percepção dos gestores das subsidiárias por país quanto aos impostos na avaliação de desempenho:

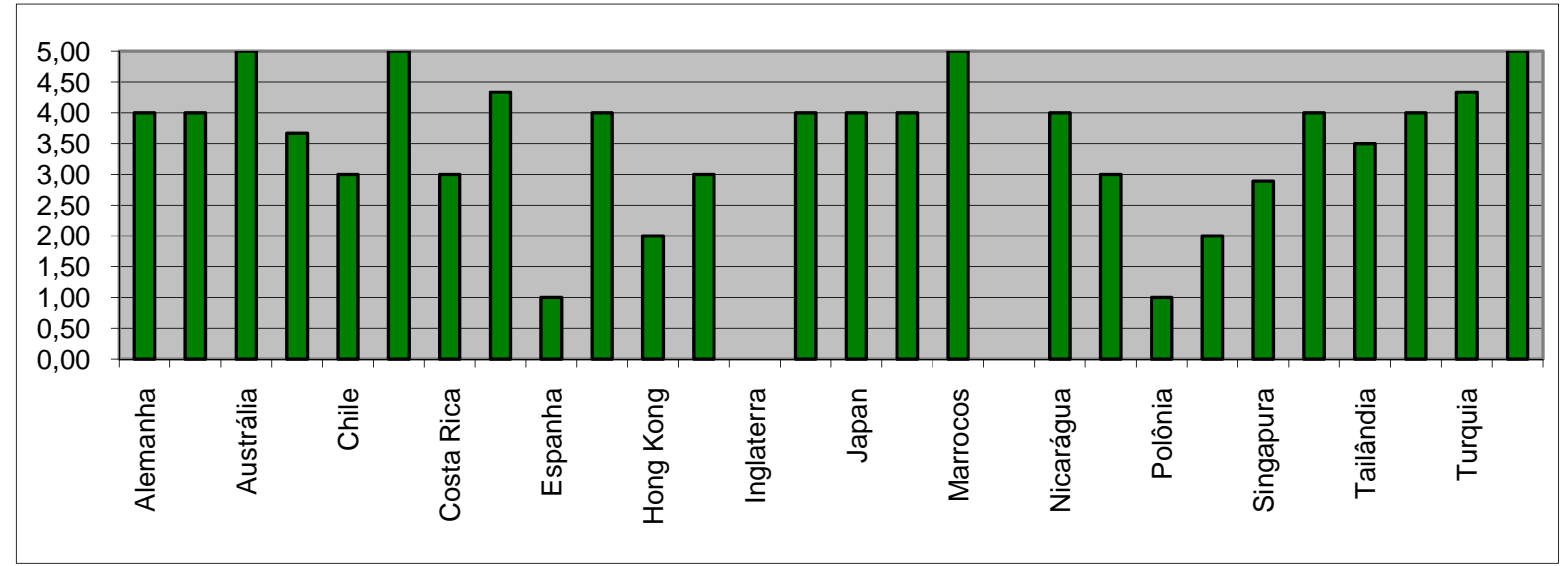

Gráfico 7 - Percepção das subsidiárias quanto aos impostos na análise de desempenho

A percepção dos países quanto aos impostos pode estar diretamente relacionada à carga tributária de cada país. Os gestores dos países que possuem forte influência da contabilidade fiscal na contabilidade financeira se sentiriam prejudicados, por estarem mais distantes das práticas contábeis seguidas pela matriz.

Aqui se notou que as subsidiárias situadas na Austrália, Colômbia, Egito, Marrocos e Venezuela demonstraram maiores dificuldades em terem seu desempenho avaliado pelo sistema de impostos norte-americano em vez de avaliado pelo local. Já as subsidiárias da Espanha e da Polônia não demonstraram dificuldades quanto a esse procedimento.

\subsection{CULTURA RELACIONADA À PERCEPÇÃO DOS GESTORES}

Este item busca relacionar os valores culturais propostos por Hofstede com as variáveis analisadas neste trabalho: conversão da moeda, cenário econômico, critérios de reconhecimento e mensuração de ativos fixos e diferidos e impostos.

Os valores culturais analisados foram:

- PDI - Distância do poder: é a extensão em que se dá a distribuição hierárquica do 
poder em instituições e organizações;

- IDV - Individualismo (versus coletivismo): é a preferência por ligações sociais mais distantes ao invés da proximidade;

- MAS - Masculinidade (versus feminilidade): é a mensuração dos privilégios por meio da visão tradicional masculina e feminina;

- UAI - Aversão à incerteza: é a mensuração do quão confortável a sociedade se sente quanto à ambigüidade e a incerteza futura.

A Tabela 3 apresenta os resultados dos cruzamentos efetuados entre essas variáveis.

Tabela 3 - Resultados dos Cruzamentos com as Variáveis Culturais

\begin{tabular}{l|c|c|c}
\hline Variáveis participantes do cruzamento & $\begin{array}{c}\text { Valor da } \\
\text { estatística }\end{array}$ & Liberdade & $\begin{array}{c}\text { Nível } \\
\text { descritivo }\end{array}$ \\
\hline PDI; Tradução da moeda & 92,647 & 80 & 0,157785 \\
\hline PDI; Cenário econômico & 82,451 & 80 & 0,403450 \\
\hline PDI; Reconhecimento ativo fixo & 84,842 & 80 & 0,334395 \\
\hline PDI; Reconhecimento ativo diferido & 78,549 & 80 & 0,524956 \\
\hline PDI; Mensuração ativo fixo & 82,452 & 80 & 0,403420 \\
\hline PDI; Mensuração ativo diferido & 76,849 & 80 & 0,579082 \\
\hline PDI; Impostos & 72,806 & 80 & 0,703190 \\
\hline IDV; Tradução da moeda & 85,778 & 76 & 0,207541 \\
\hline IDV; Cenário econômico & 79,603 & 76 & 0,366309 \\
\hline IDV; Reconhecimento ativo fixo & 69,674 & 76 & 0,682102 \\
\hline IDV; Reconhecimento ativo diferido & 76,439 & 76 & 0,464294 \\
\hline IDV; Mensuração ativo fixo & 69,792 & 76 & 0,678481 \\
\hline IDV; Mensuração ativo diferido & 69,458 & 76 & 0,688697 \\
\hline IDV; Impostos & 58,823 & 72 & 0,867958 \\
\hline MAS; Tradução da moeda & 92,647 & 76 & 0,094121 \\
\hline MAS; Cenário econômico & 83,130 & 76 & 0,269323 \\
\hline MAS; Reconhecimento ativo fixo & 88,661 & 76 & 0,151908 \\
\hline MAS; Reconhecimento ativo diferido & 76,823 & 76 & 0,452014 \\
\hline MAS; Mensuração ativo fixo & 76,907 & 76 & 0,449339 \\
\hline MAS; Mensuração ativo diferido & 77,896 & 76 & 0,418192 \\
\hline MAS; Impostos & 69,354 & 72 & 0,566510 \\
\hline UAl; Tradução da moeda & 84,732 & 76 & 0,230735 \\
\hline UAl; Cenário econômico & 80,532 & 76 & 0,339300 \\
\hline UAI; Reconhecimento ativo fixo & 82,021 & 76 & 0,298127 \\
\hline UAI; Reconhecimento ativo diferido & 75,361 & 76 & 0,499134 \\
\hline UAI; Mensuração ativo fixo & 73,719 & 76 & 0,552767 \\
\hline UAI; Mensuração ativo diferido & 69,163 & 76 & 0,697628 \\
\hline UAI; Impostos & 67,213 & 72 & 0,637660 \\
\hline
\end{tabular}

De acordo com a análise estatística Chi-Square, nenhum dos valores culturais possui relação com as variáveis analisadas. Para que houvesse qualquer relação, o nível descritivo calculado deveria ser igual ou inferior a 0,05. Quanto menor este índice, maior o índice de relação entre os valores culturais e as variáveis.

O Gráfico 8 a seguir evidencia os níveis descritivos de acordo com a análise. 0 valor cultural que mais se aproximou de uma relação foi a masculidade $\mathrm{x}$ feminilidade com a conversão da moeda, porém, mesmo assim, o nível descritivo ultrapassou 0,05 , sendo 0,094 . 


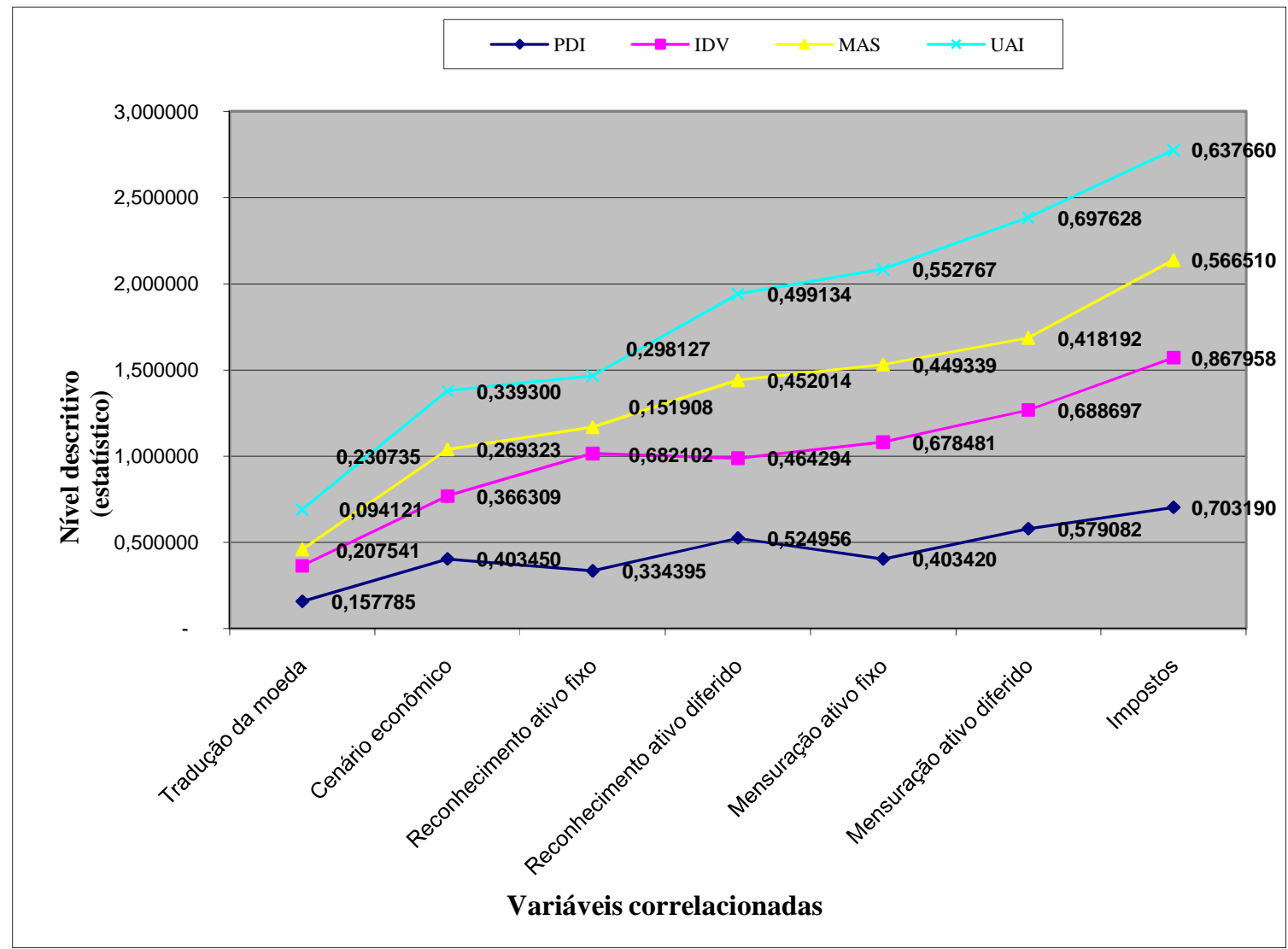

Gráfico 8 - Análise estatística de Chi-quadrado: valores culturais de Hofstede e percepção dos gestores

Conforme demonstrado no Gráfico 8, pode-se notar que todos os valores culturais seguem a mesma linha, mesmo não seguindo qualquer relação com as variáveis. Dentre os casos analisados, a maior relação encontrada está entre os valores culturais e a conversão da moeda; e a menor relação observada pode ser visualizada entre os valores culturais e os impostos.

\section{CONCLUSÃO}

Quanto ao objetivo principal do presente trabalho, que foi o de analisar os fatores que impactam a análise de desempenho de subsidiárias estrangeiras pela matriz em um determinado empreendimento multinacional, constatou-se, nesta pesquisa, que o item que gera maior insatisfação nos gestores é o referente aos impostos, tanto por parte da matriz, quanto pelas subsidiárias. Adicionalmente, as subsidiárias analisadas demonstraram, na maioria dos pontos analisados, índices de insatisfação maiores que o da matriz. Uma explicação possível para tal resultado deve-se ao fato de as normas serem regulamentadas e impostas pela matriz, devendo cada subsidiária, se adaptar aos padrões norteamericanos, independentemente das práticas contábeis locais.

$\mathrm{Na}$ busca por correlações entre a percepção dos gestores e os indicadores econômicos do país do respondente, os resultados demonstraram que quanto maior a inflação do país analisado, maior a dificuldade evidenciada pelos gestores na conversão da moeda. 
A percepção dos gestores na variável cenário econômico foi correlacionada com os fatores PIB, investimentos externos, exportações e importações. Em nenhum dos fatores pôde-se constatar um nível descritivo aceitável para afirmar que existe relação entre a variável e os fatores analisados.

Já a percepção dos países nos itens de reconhecimento e mensuração dos ativos fixos pode estar relacionada a este valor mínimo para reconhecimento. Se a subsidiária não possuir limite mínimo para reconhecer um ativo, quando fizer os ajustes determinados pela matriz, reclassificará parte de seus ativos para resultado, diminuindo seu lucro e prejudicando sua análise de desempenho, pois os índices de desempenho (ROA - Return on Assets e ROE - Return on Equity, por exemplo) diminuirão. Em termos estatísticos, a relação entre a percepção dos gestores das subsidiárias e da matriz com o critério de reconhecimento do ativo fixo e a percepção dos gestores com o critério de mensuração do ativo fixo é significante, pois apresentou nível descritivo abaixo de 0,05.

Para as análises dos critérios de reconhecimento e mensuração do ativo diferido pôde ser utilizado raciocínio similar ao caso anterior. A legislação norte-americana tende a não diferir ativos e reconhecer estes saldos no resultado. Com isso, aqueles países em que a legislação local permite o diferimento de ativos, têm seu resultado diminuído quando fazem as devidas reclassificações para enquadrarem-se aos critérios da matriz. Tal fato faz com que os índices de desempenho diminuam, prejudicando sua análise perante a matriz. Em termos estatísticos, a relação entre a percepção dos gestores das subsidiárias e da matriz com o critério de reconhecimento do ativo diferido e a percepção dos gestores com o critério de mensuração do ativo diferido é significativa, pois apresentou nível descritivo abaixo de 0,05.

A percepção dos países quanto aos impostos pode estar diretamente relacionada à carga tributária de cada país. Os países que possuem forte influência da contabilidade fiscal na contabilidade financeira, poderiam se sentir prejudicados, pois estariam mais distantes das práticas contábeis seguidas pela matriz.

A relação de percepção entre os grupos geográficos foi considerada significativa quanto aos fatores conversão da moeda, cenário econômico e mensuração do ativo fixo. Estes fatores possuem níveis descritivos menores que 0,05 , indicando que os grupos geográficos possuem percepções divergentes entre si, ou seja, cada grupo segue uma linha de percepção. Quanto aos outros fatores analisados, as percepções são diluídas entre os grupos, não demonstrando relação entre eles.

Por último, a análise dos valores culturais propostos por Hofstede não apresentou nenhuma relação com as variáveis de percepção dos gestores. Porém, pôde-se perceber que todos os valores culturais seguiram a mesma linha, mesmo não acompanhando qualquer relação com as variáveis. Dentre os casos analisados, a maior relação encontrada está entre os valores culturais e a conversão da moeda; a menor relação observada foi visualizada entre os valores culturais e os impostos.

Conclui-se, portanto, que as principais dificuldades apontadas pelos gestores na avaliação de desempenho de subsidiárias estrangeiras são os impactos dos impostos, dos critérios de diferimento dos ativos intangíveis, da conversão da moeda, da mensuração dos estoques e do resultado diferido.

Evidentemente essas conclusões, por se tratar de um estudo de caso restrito a uma companhia, não podem ser estendidas para todos os empreendimentos multinacionais. Sugere-se, no entanto, que pesquisas futuras reproduzam a presente pesquisa em outras companhias multinacionais, verificando as similaridades com os resultados aqui obtidos. 


\section{REFERÊNCIAS}

BASKERVILLE, R. F. Hofstede never studied culture. Accounting, organizations and society, v. 28, 1, p. 1-14, 2003.

BIRKINSHAW, J., HOOD, N. Multinational corporate evolution and subsidiary development. London: Mcmillan Press, 1998.

BORKOWSKI, S. C. International versus domestic managerial performance evaluation: some evidence. International journal of accounting.v. 28,2, p. 129-139, 1993.

BUCKLEY, P. J.; BURTON, F., MIRZA, H. The strategy and organization of international business. New York: St. Martin Press, 1998.

CHOI, F. D. S.; MUELLER, G. G. International Accounting. New Jersey: Prentice Hall, 1992.

; CZECHOWICZ, I. J. Assessing foreign subsidiary performance: a multinational comparison. Management international review (MIR). v. 23, 4, p. 14-25, 1983.

FISCHER, P. M.; TAYLOR, W. J., CHENG, R. H. Advanced accounting. Cincinnati: SouthWestern College Publishing, 1999.

GRIFFIN, R. W., PUTSAY, M. W. International business: a managerial perspective. New York: Addison-Wesley, 1999.

HARZING, A. W. K. Managing the multinationals: an international study of control mechanisms. Cheltenham: Edward Elgar, 1999.

HOFSTEDE, G. Cultures and organizations: software of the mind. London: McGraw-Hill, 1991.

Cultures's consequences: international differences in work - related values. Beverly Hills: Sage, 1984.

International questionnaire: VSM94, disponível em

<<http://feweb.uvt.nl/center/hofstede/english.html>>. Acesso em 14 set. 2005.

LINDHOLM, N. National culture and performance management in MNC subsidiaries. International studies of management \& organization, v. 29, 4, p. 45- 66, 2000.

NOBES, C., PARKER, R. Comparative international accounting. London: Prentice Hall Europe, 1998.

RADEBAUGH, L. H., DANIELS, J. D. International business: environment and operations. New York: Addison-Wesley, 1998.

, GRAY, S. J. International accounting and multinational enterprises. New York: John Wiley, 1997.

YU, M. C. Taiwan multinational companies and the effects fitness between subsidiary strategic roles and organizational configuration on business performance: moderating cultural differences. Journal of American Academy of Business. Cambridge,v. 7, 1, p. 213-218, 2005. 


\section{ENDEREÇO DOS AUTORES}

Centro Universitário Álvares Penteado Av. Liberdade 532 - Liberdade Sao Paulo, SP - Brasil 01502-001
Pontifícia Universidade Católica de São Paulo Faculdade de Economia e Administração Departamento de Contabilidade

R. Ministro de Godói, 969, sala 130B - Perdizes Sao Paulo, SP - Brasil

05014-901

Universidade Federal de Uberlândia Av. João Naves de Ávila, 2121 - Bloco F

Campus Santa Mônica - Santa Mônica

Uberlandia, MG - Brasil 38408-100 